\title{
About Accuracy of Calculating Deviations of Plumbing Lines in the Region of International Research Geodetic Polygon of the Western Alps
}

\section{Introduction}

At present considerable areas on continents, seas and oceans are covered with gravimetric survey. According to data of the International gravimetric bureau (Toulouse, France) gravimetric exploring of different Earth's regions on 1986 included 3362575 gravimetric points and was presented by anomalies of gravitational acceleration with a corresponding trapezium size $1^{\circ} \times 1^{\circ}$. Notice, that gravimetric exploring of the world until the middle of the nineties of the of the twentieth century. was very inhomogeneous, but during last decades degree of the Earth surface exploring became equalized considerably.

On the modern stage creation of the Earth's gravitation field models for the provision of determination of quasigeoid heights and components of deviations of plumbing lines with mean square errors correspondently $0.3-0.5 \mathrm{~m}$ and $0.5-1.0$ " is actual problem. Due to achievements in the field of space geodesy and gravimetry, considerable value of new and more precise and detailed information about the Earth's gravitational field was obtained. As a result there was achieved considerable progress on enhancement of accuracy and detailing of the Earth's gravitational field models and in the direction of development and realization of new forms of mathematical representation of gravitational anomalies.

A lot of publications of various researchers are devoted to the problem of practical calculations of gravimetric components of plumbing line deviations for the points of International research geodetic polygon in the region of the Western Alps $[1-3,5,6]$. Relief of the terrain on this polygon is quite complicated and diverse. Most gravimetric points are located on the heights 100-400 m. In the north and western north parts there are points with heights $2-3 \mathrm{~km}$ above sea level. Errors of determination of values of anomalies of gravitational acceleration $\Delta g$ for gravimetric points are $2-3$ mgal when the mean network density is 1 point per $100 \mathrm{~km}^{2}$. On the

\footnotetext{
* National University "Lviv Polytechnic", Lviv, Ukraine
} 
research territory there are large sites (up to $1600 \mathrm{~km}^{2}$ ) for which gravimetric survey was not implemented. Amplitude of majority of local anomalies $|\Delta g|=20-60 \mathrm{mgal}$. Pure errors of interpolation for research polygon are $\delta(\Delta g)=1-3 \mathrm{mgal}, \delta(\xi, \eta)=0.2-0.7^{\prime \prime}$ correspondently to anomalies and deviations of plumbing lines. In whole for polygon area the error of pure interpolation is $4-6 \mathrm{mgal}$ and error of calculating deviations of plumbing lines is 1.0-1.2". Additionally for 20 astronomic points of the research polygon the astronomic-geodetic components of plumbing line deviations were determined.

The aim of this work is generalization of some methods for calculating deviations of plumbing lines from a perspective of accuracy of their value calculation and possibilities to use high accuracy models of geopotential for calculating deviations of plumbing lines. Firstly we will dwell on the analysis of the last research where this problem is solving.

In the works [7-9] there is presented an overview of methods which are recommended for use for calculating deviations of plumbing lines in mountains. Particular attention was paid to methods which make more precise the known formulas of F. Vening Meinesz in zeroth and first approximations. Here only those methods which were approved on the models or in mountain region are described.

The method of interpolation and transformation of potential fields [1,2] is used for practical effective algorithm of calculations of gravimetric components of plumbing lines in central zone. A practical realization of this method is implemented in the system of program "Reduction-plumb"[3].

Authors [4, 6] showed that corrections of Molodensky for the zeroth approximation of anomalous potential impacts mainly not on the heights of quasigeoid but on deviation of plumbing lines in the points of the physical Earth surface. So for the practice the calculating deviations of plumbing lines in the first approximation are in the first place of importance.

In the work [5] calculating deviations of plumbing lines for the Earth's models using created for them gravimetric maps has been implemented. A comparison of calculation results with precise shows that they differ on the values to a tenth of a second.

The author [3] proposed a method of processing anomalies of gravitational acceleration for arbitrary surface of measurements. This method can be used for processing the anomalies in mountain regions, for the interpolation of values of different field characteristics, for the calculation of various field transformants including deviations of plumbing lines. It is shown that the accuracy of this method is close to optimal. The possibility of applying this method for calculating deviations of plumbing lines in the case of inhomogeneous and low-density networks of gravimetric measurements is established on the basis of a comparison with data obtained from astronomic observations and using other methods.

In the work [6] there was done an attempt to determine the order of the value of the first corrections of Molodensky into Stoke approximation of quasigeoid heights 
and deviations of plumbing lines in the mountain region of the International geodetic polygon. If calculations are done on formulas Stokes and Vening Meinesz using topographic maps and maps of anomalies in partial topographic reduction then we get the basic value of the first correction of Molodensky.

In work [7] the calculations of gravimetric components of deviations of plumbing lines for the points of International research geodetic polygon in the region of the Western Alps in zeroth approximation were done. Obtained divergences of gravimetric and astronomic-geodetic components of plumbing line deviations could be explained by principal errors of zeroth approximation formulas and errors of astronomic determinations. Additionally, authors underlined obvious shortage of gravimetric survey around some astronomic points.

\section{Exposition of Basic Material}

Solution of scientific and many applied problems of geodesy is connected with necessity of precise allowance of influence of such characteristics of the Earth's gravitational field as components of plumbing line deviations, quasigeoid heights and others.

Methods for calculation of quasigeoid heights and components of plumbing line deviations using gravimetric information can be divided on the following groups: methods of integral transformation, methods of parametric approximation, methods of statistic collocation and combined methods.

Methods of integral transformation are based on integral formulas of Stokes and Vening Meinesz:

$$
\begin{gathered}
\zeta=\frac{R}{4 \pi \gamma} \iint_{\sigma} \Delta g \cdot S(\psi) \cdot d \sigma \\
\left\{\frac{\xi}{\eta}\right\}=\frac{1}{4 \pi \gamma} \iint_{\sigma} \Delta g \cdot \frac{d S(\psi)}{d \psi} \cdot\left\{\frac{\cos A}{\sin A}\right\} d \sigma
\end{gathered}
$$

where:

$\zeta$ - quasigeoid height,

$\xi, \eta$ - components of plumbing line deviations in the plane of meridian and first vertical,

$\Delta g$ - source (initial) anomaly of gravitational acceleration in the free air,

$\sigma$ - Earth sphere,

$R$ - radius of the Earth sphere,

$\gamma$ - normal value of gravitational acceleration,

$\psi-$ spherical distance between researched and running points,

$S(\psi)$ - Stokes function. 
When modern requirements of science and practice concerning on determination of components of plumbing line deviations, the accuracy of formulas (1) and (2) is not sufficient and it is necessary to use more handy methods of calculation of L.P. Pellinen, which according to accuracy can be compared with formulas of Molodenskii in the first approximation [9]:

$$
\begin{gathered}
\left\{\frac{\xi}{\zeta}\right\}=\frac{1}{4 \pi \gamma} \iint_{\sigma}\left(\Delta g^{\prime}+2 \pi G D H+\delta g\right) \frac{d S(\psi)}{d \psi} \cdot\left\{\frac{\cos A}{\sin A}\right\} d \delta+\left\{\frac{\Delta \xi}{\Delta \eta}\right\} \\
\left\{\frac{\Delta \xi}{\Delta \zeta}\right\}=\frac{G D R^{2}}{4 \pi \gamma} \iint_{\sigma} \frac{H-H_{0}}{r_{0}}\left(\frac{1}{r_{0}}-\frac{1}{r}\right)\left\{\frac{\cos A}{\sin A}\right\} d \delta \\
\delta g=\frac{H_{0}-H}{2 \pi} R^{2} \iint_{\sigma} \frac{\Delta g^{\prime}-\Delta g_{0}}{r_{0}^{3}} d \delta
\end{gathered}
$$

where:

$\Delta g^{\prime}$ - anomaly of gravitational acceleration in partial topographic reduction,

$2 \pi \mathrm{GDH}$ - correction of Bouguer,

$H, H_{0}$ - heights of running and researched points,

$r_{0}$ - projection of on horizontal plane,

$\Delta \xi, \Delta \eta-$ corrections into components of plumbing line deviations for the influence of topographic mass.

Most useful in the case of calculating there is a method analytical continuation [4]. In this method the source (initial) anomalies are reduced from the physical Earth surface onto reference sphere of researched point using expansion in a Taylor series:

$$
\begin{gathered}
\left\{\frac{\Delta \xi}{\Delta \zeta}\right\}=\frac{1}{4 \pi \gamma} \iint_{\sigma} \Delta g \cdot \frac{d S(\psi)}{d \psi} \cdot\left\{\frac{\cos A}{\sin A}\right\} d \delta+\sum_{n=1}^{\infty} \frac{1}{4 \pi \gamma} \iint_{\sigma} g_{n} \cdot \frac{d S(\psi)}{d \psi} \cdot\left\{\frac{\cos A}{\sin A}\right\} d \delta \\
g_{0}=g_{n^{\prime}} \\
g_{n}=-\sum_{m=1}^{n}\left(H-H_{0}\right)^{m} L_{m}\left(g_{n-m}\right) \\
L_{0}(\Delta g)=\frac{1}{n} L_{1}\left|L_{n-1} \Delta(g)\right| \\
L_{1}(\Delta g)=\frac{1}{2} \iint_{\sigma} \frac{\Delta g^{\prime}-\Delta g_{0}}{r^{3}} d \delta
\end{gathered}
$$


Among methods of approximation for calculating components of plumbing line deviations the method of spherical harmonics based on known formulas of series expansion of the Earth's gravitational field characteristics according to spherical functions is most widespread:

$$
\begin{aligned}
& \xi=\frac{G M}{\gamma r^{2}} \sum_{n=r}^{N}\left(\frac{a}{r}\right)^{n} \sum_{m=0}^{n}\left(\bar{C}_{n m} \cos m \lambda+\bar{S}_{n m} \sin m \lambda\right) \frac{\partial \bar{P}_{n m}(\sin \varphi)}{\partial \varphi} \\
& \eta=-\frac{G M}{\gamma r^{2} \cos \varphi}\left(\frac{a}{r}\right)^{n} \sum_{m=0}^{n}\left(\bar{S}_{n m} \cos m \lambda-\bar{C}_{n m} \sin m \lambda\right) \frac{\overline{\partial P}_{n m}(\sin \varphi)}{\partial \varphi}
\end{aligned}
$$

where:

$$
\begin{aligned}
\bar{C}_{n m}, \bar{S}_{n m} & - \text { completely normalized expansion coefficients, } \\
\bar{P}_{n m}(\sin \varphi) & \text { - completely normalized Lagrange functions, } \\
n & \text { - harmonic degree, } \\
m & \text { - harmonic order, } \\
N & \text { - sum limit. }
\end{aligned}
$$

With the enhancement of the accuracy of global models, geopotential has got altimetric approach which is called "elimination - renovation". This approach is used for calculating quasigeoid heights and components of plumbing line deviations.

We implemented the following experimental research: for nine researched points of International research geodetic polygon in the region of the Western Alps there were determined the gravimetric components of plumbing line deviations from the models of the Earth's gravitational field EGM 2008; previously calculated gravimetric components of plumbing line deviations in zeroth approximation and in the first approximation were used for these points; difference in heights of

\begin{tabular}{|c|c|c|c|c|c|c|c|c|c|c|c|c|c|c|}
\hline \multirow{3}{*}{$\begin{array}{c}\text { Point } \\
\text { number }\end{array}$} & \multicolumn{6}{|c|}{$\begin{array}{c}\text { Gravimetric components of plumbing } \\
\text { line deviations }\end{array}$} & \multicolumn{8}{|c|}{$\begin{array}{l}\text { Astronomic-geodetic components of plumbing line } \\
\text { deviations }\end{array}$} \\
\hline & \multicolumn{2}{|c|}{$\begin{array}{l}\text { model } \\
\text { values }\end{array}$} & \multicolumn{2}{|c|}{ on Ostach } & \multicolumn{2}{|c|}{ on Aronov } & \multicolumn{2}{|c|}{$\begin{array}{c}\text { true } \\
\text { values }\end{array}$} & \multicolumn{2}{|c|}{$\begin{array}{l}\text { model } \\
\text { values }\end{array}$} & \multicolumn{2}{|c|}{ on Ostach } & \multicolumn{2}{|c|}{ on Aronov } \\
\hline & $\xi^{\prime \prime} g r$ & $\eta " g r$ & $\xi^{\prime \prime} g r$ & $\eta^{\prime \prime} g r$ & $\xi^{\prime \prime} g r$ & $\eta " g r$ & $\xi^{\prime \prime}$ ag & $\eta^{\prime \prime}$ ag & $\xi " a g$ & $\eta " a g$ & $\xi^{\prime \prime}$ ag & $\eta^{\prime \prime}$ ag & $\xi " a g$ & $\eta^{\prime \prime} a g$ \\
\hline 14 & -25.5 & 21.5 & -23.3 & 16.5 & -20.5 & 15.3 & -26.3 & 17.1 & -25.2 & 21.5 & -23.2 & 16.5 & -19.9 & 15.3 \\
\hline 20 & -15.2 & 4.9 & -15.9 & 1.6 & -15.8 & 1.6 & -20.9 & 1.0 & -15.2 & 4.9 & -15.9 & 1.6 & -15.8 & 1.6 \\
\hline 30 & -20.5 & 28.4 & -21.9 & 27.5 & -20.4 & 26.3 & -24.8 & 23.3 & -20.4 & 28.4 & -21.9 & 27.5 & -20.3 & 26.3 \\
\hline
\end{tabular}
the observation points was considered. Then astronomic-geodetic components of plumbing line deviations on these points were calculated and compared with their known values according to astronomic and geodetic coordinates. The results of the experimental research are shown in Tables 1-3. Table 1 displays the values of gravimetric and astronomic-geodetic components of plumbing line deviations.

Table 1. Values of plumbing line deviations determined by different methods 
Table 1. cont.

\begin{tabular}{|c|c|c|c|c|c|c|c|c|c|c|c|c|c|c|c|}
\hline \multirow{3}{*}{$\begin{array}{l}\text { Point } \\
\text { number }\end{array}$} & \multicolumn{6}{|c|}{$\begin{array}{l}\text { Gravimetric components of plumbing } \\
\text { line deviations }\end{array}$} & \multicolumn{9}{|c|}{$\begin{array}{l}\text { Astronomic-geodetic components of plumbing line } \\
\text { deviations }\end{array}$} \\
\hline & \multicolumn{2}{|c|}{$\begin{array}{l}\text { model } \\
\text { values }\end{array}$} & \multicolumn{2}{|c|}{ on Ostach } & \multicolumn{2}{|c|}{ on Aronov } & \multicolumn{2}{|c|}{$\begin{array}{c}\text { true } \\
\text { values }\end{array}$} & \multicolumn{3}{|c|}{$\begin{array}{l}\text { model } \\
\text { values }\end{array}$} & \multicolumn{2}{|c|}{ on Ostach } & \multicolumn{2}{|c|}{ on Aronov } \\
\hline & $\xi " g r$ & $\eta^{\prime \prime} g 1$ & $\xi^{\prime \prime} g r$ & $\eta^{\prime \prime} g r$ & $\xi^{\prime \prime} \mathrm{g}$ & $\eta^{\prime \prime} g$ & $\xi^{\prime \prime} a$ & & & $\xi^{\prime \prime a g}$ & ๆ"ag & $\xi^{\prime \prime} a g$ & $\eta$ "ag & $\xi^{\prime \prime} \mathrm{ag}$ & $\eta^{\prime \prime}$ ag \\
\hline 33 & -4.5 & 17.1 & -4.2 & 17.0 & -4.2 & 17.1 & -8.3 & & & -4.4 & 17.1 & -4.2 & 17.0 & -4.1 & 17.1 \\
\hline 34 & -8.1 & 27.0 & -7.3 & 25.9 & -7.0 & 24.2 & -11 & 24 & & -8.0 & 27.0 & -7.3 & 25.9 & -6.9 & 24.2 \\
\hline 37 & 4.0 & 4.8 & 1.1 & 4.6 & 1.1 & 3.2 & -2 & & & 4.0 & 4.8 & 1.2 & 4.6 & 1.2 & 3.2 \\
\hline 38 & 11.5 & -0.1 & 9.5 & -1.4 & 8.7 & 0.0 & 4.0 & & & 11.6 & -0.1 & 9.5 & -1.4 & 8.7 & 0.0 \\
\hline 43 & 12.2 & 17.2 & 12.3 & 18.9 & 10. & 17.9 & 13. & & & 12.2 & 17.2 & 12.3 & 18.9 & 10.6 & 17.9 \\
\hline 45 & -0.2 & 0.0 & -2.6 & -0.6 & -3. & -1.0 & -5. & -1 & & -0.1 & 0.0 & -2.6 & -0.6 & -3.4 & -1.0 \\
\hline
\end{tabular}

Table 2 displays differences between real and calculated values of astronomic-geodetic deviations of plumbing line obtained by different calculation methods.

Table 2. Differences between real and calculated values of astronomic-geodetic deviations of plumbing line obtained by different calculation methods

\begin{tabular}{|c|c|c|c|c|c|c||}
\hline \multirow{2}{*}{$\begin{array}{c}\text { Point } \\
\text { number }\end{array}$} & \multicolumn{2}{|c|}{$\begin{array}{c}\text { Differences of true and } \\
\text { model values }\end{array}$} & \multicolumn{2}{c|}{$\begin{array}{c}\text { Differences of true values } \\
\text { and calculated on Ostach }\end{array}$} & \multicolumn{2}{c|}{$\begin{array}{c}\text { Differences of true values } \\
\text { and calculated on Aronov }\end{array}$} \\
\cline { 2 - 7 } & $\xi_{a g}^{\text {true }}-\xi_{a g}^{\text {mod }}$ & $\eta_{a g}^{\text {true }}-\eta_{a g}^{\text {mod }}$ & $\xi_{a g}^{\text {true }}-\xi_{a g}^{\text {Ost }}$ & $\eta_{a g}^{\text {true }}-\eta_{a g}^{\text {Ost }}$ & $\xi_{a g}^{\text {true }}-\xi_{a g}^{A r}$ & $\eta_{a g}^{\text {true }}-\eta_{a g}^{A r}$ \\
\hline \hline 14 & -1.1 & -4.4 & -3.1 & 0.6 & -6.4 & 1.8 \\
\hline 20 & -5.7 & -3.9 & -5.0 & -0.6 & -5.1 & -0.6 \\
\hline 30 & -4.4 & -5.1 & -2.9 & -4.2 & -4.5 & -3.0 \\
\hline 33 & -3.9 & -2.7 & -4.1 & -2.6 & -4.2 & -2.7 \\
\hline 34 & -3.4 & -2.1 & -4.1 & -1.0 & -4.5 & 0.7 \\
\hline 37 & -6.9 & -2.6 & -4.1 & -2.4 & -4.1 & -1.0 \\
\hline 38 & -7.6 & -8.8 & -5.5 & -7.5 & -4.7 & -8.9 \\
\hline 43 & 1.2 & 6.0 & 1.1 & 4.3 & 2.8 & 5.3 \\
\hline 45 & -5.5 & -1.7 & -3.0 & -1.1 & -2.2 & -0.7 \\
\hline
\end{tabular}

Accuracy estimation of calculation results is shown in Table 3.

Table 3. Errors of calculated values of plumbing line deviations

\begin{tabular}{|c|c|c|c|c|c||}
\hline \multicolumn{2}{||c|}{$\begin{array}{c}\text { Errors of model values } \\
\text { of plumbing line deviations }\end{array}$} & \multicolumn{2}{|c|}{$\begin{array}{c}\text { Errors of plumbing line } \\
\text { deviations calculated on Ostach }\end{array}$} & \multicolumn{2}{c|}{$\begin{array}{c}\text { Errors of plumbing line } \\
\text { deviations calculated on Aronov }\end{array}$} \\
\hline \hline$m^{\prime \prime} \xi$ & $m^{\prime \prime} \eta$ & $m^{\prime \prime} \xi$ & $m^{\prime \prime} \eta$ & $m^{\prime \prime} \xi$ & $m^{\prime \prime} \eta$ \\
\hline 4.90 & 4.65 & 3.86 & 3.46 & 4.42 & 3.79 \\
\hline
\end{tabular}




\section{Conclusions}

Discrepancies between true and calculated components of plumbing line deviations can mainly be explained by errors of astronomic determination as components of plumbing line deviations includes the influence of the zeroth and the first approximation of the field of anomalies.

Considering height differences considerably improves the accuracy of the gravimetric components of plumbing line deviations to 1 " if relief corrections using gravimetric maps of Bouguer anomalies are taken into account.

Differences between model end true components of plumbing line deviations can be explained by not considering the influence of the central and closed zone of the anomaly field.

\section{References}

[1] Aronov V.I., Gordin V.M.: Ob odnom sposobe interpolyatsii anomalii i vychisleniy gravimetricheskikh ukloneniy otvesa v rayone Zapadnykh Al'p [Об одном способе интерполяции аномалии и вычислений гравиметрических уклонений отвеса в районе Западных Альп]. Geofizicheskiy byulleten', 24, 1971, pp. 19-24.

[2] Aronov V.I., Gordin V.M., Beleykov N.Ye., Shirginova A.I.: Programma dlya vychisleniya gravimetricheskikh ukloneniy otvesa $v$ tsentral'noy zone [Программа для вычисления гравиметрических уклонений отвеса в центральной зоне]. Izvestiye vuzov, Geodeziya i aerofotos'yemka, 4, 1971, pp. 41-45.

[3] Aronov V.I.: Obrabotka na EVM znacheniy anomaliy sily tyazhesti pri proizvol'nom rel'yefe poverkhnostey nablyudeniy [Обработка на ЭВМ значений аномалий силы тяжести при произвольном рельефе поверхностей наблюдений]. Nedra, Moskva 1976.

[4] Marich M.I.: O vychislenii otvesa na fizicheskoy poverkhnosti Zemli [О вычислении отвеса на физической поверхности Земли]. Geodeziya, kartografiya i aerofotos'yemka, no. 18, 1973, pp. 24-28.

[5] Marich M.I., Gudz I.N., Dvulit P.D.: Opyt vychisleniya ukloneniy otvesa na modelyakh Zemli [Опыт вычисления уклонений отвеса на моделях Земли]. Geodeziya, kartografiya i aerofotos'yemka, no. 18, 1973, pp. 29-33.

[6] Marich M.I., Gudz I.N.: O vychislenii vysot kvazigeoida i ukloneniy otvesa $v$ gornom rayone [О вычислении высот квазигеоида и укдонений отвеса в горном районе]. Geodeziya, kartografiya i aerofotos'yemka, no. 34, 1981, pp. 65-68. 
[7] Ostach O.M., Pellinen L.P.: Vychisleniye gravimetricheskikh ukloneniy otvesa $v$ nulevom priblizhenii $v$ rayone Zapadnykh Al'p [Вычисление гравиметрических уклонений отвеса в нулевом приближении в районе Западных Альп]. Geofizicheskiy byulleten', 24, 1971, pp. 13-18.

[8] Pellinen L.P.: Comparison of different methods for computing the plumb-line deflections in the mountainous areas. Bulletin géodésique, vol. 89, issue 1,1968, pp. 345-354.

[9] Pellinen L.P.: O vychislenii ukloneniy otvesa $i$ vysot kvazigeoida $v$ gorakh [O вычислении уклонений отвеса и высот квазигеоида в горах]. Trudy TSNIIGAIK, vyp. 176, 1969, pp. 99-112. 